EXTENDED REPORT

\title{
Body composition and knee cartilage properties in healthy, community-based adults
}

\section{Yuanyuan Wang, Anita E Wluka, Dallas R English, Andrew J Teichtahl, Graham G Giles, Richard O'Sullivan, Flavia M Cicuttini}

See end of article for authors' affiliations

Correspondence to: Professor F Cicuttini, Department of Epidemiology and Preventive Medicine, Monash University, Central and Eastern Clinical School, Alfred Hospital, Melbourne, VIC 3004, Australia; flavia. cicuttini@med.monash.edu. au

Accepted 13 January 2007 Published Online First 29 January 2007

\begin{abstract}
Background: Although obesity is widely accepted as a risk factor for knee osteoarthritis, whether weight per se or the specific components of body composition are the major determinants of properties of articular knee cartilage is unclear.

Objective: To examine associations between anthropometric and body composition measures and knee cartilage properties in healthy adults.

Methods: 297 healthy adults with no clinical knee osteoarthritis were recruited from an existing communitybased cohort. Anthropometric measures and body composition, including fat-free mass and fat mass assessed using bioelectrical impedance analysis, were measured at baseline (1990-4) and current follow-up (2003-4). Tibial cartilage volume and tibiofemoral cartilage defects were assessed using MRI at follow-up. Results: After adjustment for potential confounders, baseline and current fat-free mass, independent of fat mass, were positively associated with tibial cartilage volume (all $p<0.001$ ). Increased fat-free mass over the time period was positively associated with tibial cartilage volume $(p<0.001)$. Current fat mass was negatively associated with tibial cartilage volume $(p=0.004)$. Baseline and current fat mass were weakly associated with increased tibiofemoral cartilage defects $(p=0.06$ and $p=0.07$, respectively), independent of fat-free mass. Conclusion: The findings suggest a beneficial effect of fat-free mass, but a deleterious effect of fat mass, on knee cartilage properties in healthy adults. This suggests that weight-loss programmes aimed at reducing fat mass but maintaining muscle mass may be important in preventing the onset and/or progression of knee osteoarthritis.
\end{abstract}

as a valid, accurate and reproducible tool for measuring articular cartilage volume ${ }^{13} 14$ and cartilage defects, ${ }^{15}{ }^{16}$ which have been shown to have an important role in OA. ${ }^{14-16}$

The aim of this study was to determine whether baseline (about 10 years earlier) and current anthropometric and body composition measures and their change over time are related to properties of articular knee cartilage in a community-based population of healthy adults with no clinical OA.

\section{PATIENTS AND METHODS}

\section{Subjects}

The study was conducted within the Melbourne Collaborative Cohort Study (MCCS), which is a prospective cohort study of 41528 community-based people, aged 40-69 years at recruitment which occurred between 1990 and 1994, with the aim of examining the role of lifestyle factors in the risk of cancer and heart disease. ${ }^{17}$ Participants were recruited from MCCS. As our intent was to investigate subjects with no significant current or past knee disease, potential subjects were excluded for any of the following reasons: a clinical diagnosis of knee $\mathrm{OA}$ as defined by American College of Rheumatology criteria ${ }^{18}$; knee pain lasting for $>24 \mathrm{~h}$ in the last 5 years; a previous knee injury requiring non-weight bearing treatment for $>24$ h or surgery (including arthroscopy); a malignancy; unable to complete the study (eg, proposed relocation); a history of any form of arthritis diagnosed by a medical practitioner. A further exclusion criterion was a contraindication to MRI including pacemaker, metal sutures, presence of shrapnel or iron filings in the eye, or claustrophobia. We invited subjects who fulfilled

Abbreviations: $B M I$, body mass index; FFM, fat-free mass; FM, fat mass MCCS, Melbourne Collaborative Cohort Study; OA, osteoarthritis; WHR, waist-to-hip ratio 
our inclusion criteria and had attended the first year of round 3 follow-up of the MCCS, which started in 2003. We used quota sampling whereby recruitment ceased when our target sample of about 300 subjects was achieved. The study was approved by The Cancer Council Victoria Human Research Ethics Committee and the Standing Committee on Ethics in Research Involving Humans of Monash University. All participants gave written informed consent.

\section{Anthropometric measures}

At the MCCS baseline (1990-4), ${ }^{17}$ height, weight, waist and hip circumferences were measured using standardised written protocols. ${ }^{19}$ Baseline BMI (weight $/$ height ${ }^{2}, \mathrm{~kg} / \mathrm{m}^{2}$ ) and WHR were calculated from these data. Weight was measured using electronic scales with bulky clothing removed at the current follow-up (2003-4). Current BMI was calculated.

Bioelectrical impedance analysis was performed with a single-frequency $(50 \mathrm{kHz}$ ) electric current produced by a BIA101A RJL system analyser (RJL systems, Detroit, Michigan, USA), at baseline and current follow-up. Resistance and reactance were measured with subjects in the supine position. We used bioimpedance analysis to estimate non-adipose mass, hereafter termed fat-free mass (FFM), as $9.1536+(0.4273$ $\times$ height ${ }^{2} /$ resistance $)+(0.1926 \times$ weight $)+(0.0667 \times$ reactance $)$ for men, and $7.7435+\left(0.4542 \times\right.$ height $^{2} /$ resistance $)+(0.119 \times$ weight $)$ $+(0.0455 \times$ reactance $)$ for women..$^{20}$ Adipose mass, hereafter termed fat mass (FM; weight - FFM) and percentage of fat (FM divided by weight) were subsequently calculated.

\section{MRI and the measurement of cartilage volume and cartilage defects at current follow-up}

At the current follow-up during 2003-4, each subject had an MRI performed on the dominant knee (defined as the leg used to step-off from when walking was initiated). Knees were imaged on a $1.5 \mathrm{~T}$ whole-body magnetic resonance unit (Philips 1.5 Tesla Intera; Philips Medical Systems, Eindhoven, the Netherlands) using a commercial transmit-receive extremity coil, with sagittal $\mathrm{T}_{1}$-weighted fat-suppressed three-dimensional gradient recall acquisition as previously described..$^{13}$

Tibial cartilage volume was determined by image processing using Osiris software (Geneva, Switzerland) as previously described. ${ }^{13}{ }^{14}$ The coefficients of variation for cartilage volume measures were $2.1 \%$ for medial tibial and $2.2 \%$ for lateral tibial cartilage. $^{14}$

Cartilage defects were graded on the MR images with a classification system as previously described ${ }^{15}{ }^{16}$ for the medial and lateral tibial and femoral cartilages. A cartilage defect was identified as present if there was irregularity on the cartilage surface or bottom with loss of cartilage thickness on at least two consecutive slices. Intraobserver and interobserver reliability assessed in $50 \mathrm{MR}$ images (expressed as intraclass correlation coefficient) were 0.90 and 0.90 for the medial tibiofemoral compartment and 0.89 and 0.85 for the lateral tibiofemoral compartment, respectively. ${ }^{16}$

Tibial plateau cross-sectional area was used as a measure of tibial bone size. It was directly measured from images reformatted in the axial plane using Osiris software as previously described. ${ }^{13}{ }^{14}$ Coefficients of variation for the medial and lateral tibial plateau areas were $2.3 \%$ and $2.4 \%$, respectively. ${ }^{14}$

\section{Statistical analysis}

Outcomes were tibial cartilage volume and the presence of tibiofemoral cartilage defects assessed at current follow-up. Tibial cartilage volume was assessed for normality, thus linear regression was used. The presence/absence of cartilage defects was a dichotomous outcome, thus logistic regression was used. Multiple regression models were constructed to explore the relationship between anthropometric and body composition measures and knee cartilage properties, with adjustment for the potential confounders of age, gender and tibial plateau bone area (for tibial cartilage volume only). In terms of anthropometric and body composition measures, we analysed baseline variables, current follow-up variables, and the change in these variables (current follow-up values - baseline values) separately. To further examine body mass distribution as a predictor of the different knee cartilage features, we fitted FFM and FM simultaneously as continuous variables in the same model. $\mathrm{p}<0.05$ were considered to be significant. All analyses were performed using the SPSS statistical package (standard version 14.0; SPSS, Chicago, Illinois, USA).

\section{RESULTS}

Table 1 presents the characteristics of the 297 participants (age range 50-79 years (mean (SD) 58.0 (5.5) years). Cartilage defects were more common in women (124 (66.7\%) compared with $60(54.1 \%)$ in men). There were no significant differences between this population and the original MCCS population, which has the following profile: $61 \%$ women, mean (SD) age 57.8 (3.0) years and BMI 25.7 (3.8) $\mathrm{kg} / \mathrm{m}^{2}$. There were no significant differences in dietary intake or other health-related behaviours (data not shown). There were current body

Table 1 Characteristics of study subjects $(n=297)$ at baseline $(1990-4)$ and follow-up (2003-4)

\begin{tabular}{llll}
\hline & At baseline & At follow-up & p Value* \\
\hline Age (years) & - & $58.0(5.5)$ & - \\
Female & - & $186(63 \%)$ & - \\
Height $(\mathrm{cm})$ & $168.1(9.0)$ & - & - \\
Weight $(\mathrm{kg})$ & $71.3(13.3)$ & $73.4(14.3) \dagger$ & $<0.001$ \\
Body mass index $\left(\mathrm{kg} / \mathrm{m}^{2}\right)$ & $25.2(3.8)$ & $25.9(4.3) \dagger$ & $<0.001$ \\
Waist circumference $(\mathrm{cm})$ & $80.2(12.6)$ & - & - \\
Hip circumference $(\mathrm{cm})$ & $98.9(7.8)$ & - & - \\
Waist-to-hip ratio & $0.81(0.09)$ & - & - \\
Fat-free mass $(\mathrm{kg})$ & $47.0(9.7)$ & $46.4(10.2) \ddagger$ & 0.78 \\
Fat mass $(\mathrm{kg})$ & $24.3(8.4)$ & $26.6(8.9) \ddagger$ & $<0.001$ \\
Tibial cartilage volume $\left(\mathrm{mm}^{3}\right)$ & - & $3731(1116)$ & - \\
Tibial plateau bone area $\left(\mathrm{mm}^{2}\right)$ & - & $3301(474)$ & - \\
Presence of cartilage defects & - & $184(62 \%)$ & - \\
\hline
\end{tabular}

Except where indicated, values are mean (SD)

${ }^{*}$ Difference in variables between baseline and current follow-up, using paired-samples $t$ test.

†Data available on 294 subjects.

†Data available on 233 subjects. 
Table 2 Relationship between anthropometric and body composition measures and tibial cartilage volume

\begin{tabular}{|c|c|c|c|c|c|c|}
\hline & $\begin{array}{l}\text { Univariate analysis } \\
\text { (regression coefficient } \\
(95 \% \mathrm{Cl}))\end{array}$ & p Value & $\begin{array}{l}\text { Multivariate analysis } \\
\text { (regression coefficient } \\
(95 \% \mathrm{CI}))^{*}\end{array}$ & p Value & $\begin{array}{l}\text { Multivariate analysis } \\
\text { (regression coefficient } \\
(95 \% \mathrm{Cl}) \mid \dagger\end{array}$ & p Value \\
\hline \multicolumn{7}{|l|}{ Variables at baseline (1990-4) } \\
\hline Weight (kg) & 49.6 (41.8 to 57.3$)$ & $<0.001$ & $5.8(-1.7$ to 13.4$)$ & 0.13 & - & \\
\hline Body mass index $\left(\mathrm{kg} / \mathrm{m}^{2}\right)$ & 52.5 (19.4 to 85.5$)$ & 0.002 & $-2.9(-22.7$ to 16.9$)$ & 0.77 & - & \\
\hline Waist circumference $(\mathrm{cm})$ & 45.0 (36.3 to 53.7$)$ & $<0.001$ & $-0.01(-7.5$ to 7.5$)$ & 1.00 & - & \\
\hline Waist-to-hip ratio (\%) & 68.2 (56.9 to 79.4$)$ & $<0.001$ & $-2.0(-13.8$ to 9.9$)$ & 0.74 & $-3.7(-16.9$ to 9.6$)$ & 0.59 \\
\hline Fat-free mass $(\mathrm{kg})$ & $92.8(85.0$ to 100.6$)$ & $<0.001$ & 41.9 (22.7 to 61.1$)$ & $<0.001$ & 48.4 (27.9 to 68.9$)$ & $<0.001$ \\
\hline Fat mass $(\mathrm{kg})$ & $0.5(-14.7$ to 15.6$)$ & 0.95 & $-0.4(-9.8$ to 9.1$)$ & 0.94 & $-8.7(-18.5$ to 1.1$)$ & 0.08 \\
\hline \multirow{2}{*}{\multicolumn{7}{|c|}{ Variables at current follow-up $(2003-4)$}} \\
\hline & & & & & & \\
\hline Weight (kg) & $44.0(36.5$ to 51.4$)$ & $<0.001$ & $6.7(0.04$ to 13.3$)$ & 0.05 & - & \\
\hline Body mass index $\left(\mathrm{kg} / \mathrm{m}^{2}\right)$ & 40.9 (11.0 to 70.8$)$ & 0.01 & $3.1(-14.4$ to 20.6$)$ & 0.73 & - & \\
\hline Fat-free mass $(\mathrm{kg})$ & $88.9(81.2$ to 96.6$)$ & $<0.001$ & $42.6(22.6$ to 62.6$)$ & $<0.001$ & 63.5 (39.3 to 87.6$)$ & $<0.001$ \\
\hline Fat mass $(\mathrm{kg})$ & $5.5(-10.3$ to 21.3$)$ & 0.49 & $0.3(-8.9$ to 9.5$)$ & 0.95 & $-15.9(-26.6$ to -5.3$)$ & 0.004 \\
\hline \multicolumn{7}{|c|}{ Change in the following variables } \\
\hline Weight (kg) $\ddagger$ & $5.8(-18.7$ to 30.4$)$ & 0.64 & $9.5(-4.7$ to 23.8$)$ & 0.19 & - & \\
\hline Body mass index $\left(\mathrm{kg} / \mathrm{m}^{2}\right) \ddagger$ & $-5.2(-73.7$ to 63.3$)$ & 0.88 & $25.1(-14.7$ to 64.9$)$ & 0.22 & & \\
\hline Fat-free mass $(\mathrm{kg}) \neq$ & 53.4 (3.9 to 102.9$)$ & 0.03 & $30.8(2.7$ to 58.9$)$ & 0.03 & 60.8 (28.6 to 93.0$)$ & $<0.001$ \\
\hline Fat mass $(\mathrm{kg}) \ddagger$ & $7.4(-25.3$ to 40.2$)$ & 0.66 & $8.9(-9.1$ to 26.9$)$ & 0.33 & $-1.5(-18.8$ to 15.9$)$ & 0.87 \\
\hline \multicolumn{7}{|c|}{$\begin{array}{l}\text { *Change in tibial cartilage volume }\left(\mathrm{mm}^{3}\right) \text { per unit increase in the respective anthropometric and body composition measure after adjustment for age, gender and tibio } \\
\text { plateau bone area in the regression equation. } \\
\text { †Change in tibial cartilage volume }\left(\mathrm{mm}^{3}\right) \text { per unit increase in the respective anthropometric and body composition measure after adjustment for fat-free mass and fo } \\
\text { mass, ie, including age, gender, tibial plateau bone area, fat-free mass and fat mass in the regression equation. } \\
\ddagger \text { Adjusted for age, gender, tibial plateau bone area and respective baseline variable in the regression equation. }\end{array}$} \\
\hline
\end{tabular}

composition measures for $233(78.5 \%)$ subjects. This group had lower baseline weight $(\mathrm{p}=0.05)$ and BMI $(\mathrm{p}=0.01)$ than those without current body composition measures. There were no significant differences in terms of baseline height $(p=0.87)$, FFM $(p=0.06)$ and FM $(p=0.41)$ between the two groups. There were significant increases in body weight, BMI and FM (all $\mathrm{p}<0.001)$, but no significant change in FFM $(\mathrm{p}=0.78)$ over the 10 -year period.

\section{Relationship between anthropometric and body composition measures and tibial cartilage volume}

The associations between baseline anthropometric and body composition measures and current tibial cartilage volume were examined (table 2). In univariate analyses, body weight, BMI, waist circumference, WHR and FFM were all positively associated with tibial cartilage volume. Percentage of fat was negatively associated with tibial cartilage volume. In multivariate analyses adjusted for age, gender and tibial plateau bone area, only FFM remained positively associated with tibial cartilage volume $(\mathrm{p}<0.001)$. After adjustment for FFM and FM, FFM was positively associated with tibial cartilage volume $(p<0.001)$. FM was weakly negatively associated with tibial cartilage volume $(p=0.08)$. WHR was not significantly associated with tibial cartilage volume $(\mathrm{p}=0.59)$.

Similar results were found when current anthropometric and body composition measures were examined (table 2). Current FFM was positively associated with tibial cartilage volume $(\mathrm{p}<0.001)$, and body weight was weakly positively associated with tibial cartilage volume $(\mathrm{p}=0.05)$ in multivariate analyses. After adjustment for FFM and FM, FFM was positively

Table 3 Relationship between anthropometric and body composition measures and presence of cartilage defects

\begin{tabular}{|c|c|c|c|c|c|c|}
\hline & $\begin{array}{l}\text { Univariate analysis } \\
\text { (odds ratio }(95 \% \mathrm{CI}) \text { ) }\end{array}$ & p Value & $\begin{array}{l}\text { Multivariate analysis } \\
\text { (odds ratio }(95 \% \mathrm{Cl}))^{*}\end{array}$ & p Value & $\begin{array}{l}\text { Multivariate analysis } \\
\text { (odds ratio }(95 \% \mathrm{Cl}) \dagger\end{array}$ & p Value \\
\hline \multicolumn{7}{|l|}{ Variables at baseline (1990-4) } \\
\hline Weight (kg) & 1.01 (0.99 to 1.03 ) & 0.25 & $1.03(1.01$ to 1.06$)$ & 0.01 & - & \\
\hline Body mass index $\left(\mathrm{kg} / \mathrm{m}^{2}\right)$ & 1.07 (1.00 to 1.14$)$ & 0.05 & 1.09 (1.01 to 1.16$)$ & 0.02 & - & \\
\hline Waist circumference $(\mathrm{cm})$ & 1.01 (0.99 to 1.03 ) & 0.28 & 1.04 (1.01 to 1.06$)$ & 0.01 & - & \\
\hline Waist-to-hip ratio (\%) & 1.00 (0.98 to 1.03$)$ & 0.87 & 1.05 (1.01 to 1.09$)$ & 0.02 & 1.03 (0.98 to 1.08 ) & 0.21 \\
\hline Fat-free mass (kg) & $0.99(0.96$ to 1.01$)$ & 0.30 & $1.06(1.00$ to 1.12$)$ & 0.04 & $1.03(0.97$ to 1.10$)$ & 0.34 \\
\hline Fat mass $(\mathrm{kg})$ & 1.05 (1.02 to 1.08$)$ & 0.003 & 1.04 (1.01 to 1.08 ) & 0.01 & 1.04 (1.00 to 1.07 ) & 0.06 \\
\hline \multirow{2}{*}{\multicolumn{7}{|c|}{ Variables at current follow-up (2003-4) }} \\
\hline & & & & & & \\
\hline Weight (kg) & 1.01 (0.99 to 1.03 ) & 0.22 & 1.03 (1.01 to 1.05 ) & 0.01 & - & \\
\hline Body mass index $\left(\mathrm{kg} / \mathrm{m}^{2}\right)$ & 1.06 (1.00 to 1.12$)$ & 0.05 & 1.07 (1.01 to 1.14$)$ & 0.03 & - & \\
\hline Fat-free mass $(\mathrm{kg})$ & 0.99 (0.96 to 1.01$)$ & 0.25 & 1.07 (1.01 to 1.13$)$ & 0.03 & $1.02(0.95$ to 1.10$)$ & 0.57 \\
\hline Fat mass $(\mathrm{kg})$ & 1.05 (1.02 to 1.09$)$ & 0.004 & 1.05 (1.01 to 1.08$)$ & 0.01 & 1.04 (1.00 to 1.09$)$ & 0.07 \\
\hline \multicolumn{7}{|l|}{ Change in the following variables } \\
\hline Weight (kg)‡ & 1.01 (0.97 to 1.06$)$ & 0.61 & 1.01 (0.97 to 1.07$)$ & 0.57 & - & \\
\hline Body mass index $\left(\mathrm{kg} / \mathrm{m}^{2}\right) \ddagger$ & 1.03 (0.91 to 1.17$)$ & 0.63 & 1.04 (0.90 to 1.18 ) & 0.62 & - & \\
\hline Fat-free mass $(\mathrm{kg}) \ddagger$ & 1.01 (0.92 to 1.11$)$ & 0.82 & 1.04 (0.94 to 1.14$)$ & 0.47 & 0.98 (0.87 to 1.10$)$ & 0.71 \\
\hline Fat mass $(\mathrm{kg}) \ddagger$ & $1.04(0.97$ to 1.10$)$ & 0.27 & $1.04(0.97$ to 1.11$)$ & 0.25 & $1.03(0.97$ to 1.10$)$ & 0.35 \\
\hline
\end{tabular}

*Odds ratio of cartilage defects per unit increase in the respective anthropometric and body composition measure after adjustment for age and gender in the regression equation.

†Odds ratio of cartilage defects per unit increase in the respective anthropometric and body composition measure after adjustment for fat-free mass and fat mass, ie, including age, gender, fat-free mass and fat mass in the regression equation.

$\ddagger$ Adjusted for age, gender and respective baseline variable in the regression equation. 
associated with tibial cartilage volume $(p<0.001)$. FM was negatively associated with tibial cartilage volume $(\mathrm{p}=0.004)$.

Increase in FFM over the time period was positively associated with tibial cartilage volume in both univariate and multivariate analyses (all $\mathrm{p}=0.03$ ). This association persisted after adjustment for both FFM and FM $(\mathrm{p}<0.001)$. Changes in body weight, BMI and FM were not significantly associated with tibial cartilage volume (table 2).

\section{Relationship between anthropometric and body composition measures and the presence of tibiofemoral cartilage defects}

The associations between baseline anthropometric and body composition measures and the presence of current tibiofemoral cartilage defects were examined (table 3). In univariate analyses, BMI, FM and percentage of fat were positively associated with the presence of tibiofemoral cartilage defects. In multivariate analyses adjusted for age and gender, body weight, BMI, waist circumference, WHR, FFM, FM and percentage of fat were all positively associated with the presence of tibiofemoral cartilage defects, with odds ratios ranging from 1.03 to 1.09 (all $\mathrm{p} \leqslant 0.04$ ). After adjustment for FFM and FM, FM was weakly positively associated with the presence of tibiofemoral cartilage defects $(p=0.06)$. FFM $(p=0.34)$ and WHR $(p=0.21)$ were no longer significantly associated with the presence of tibiofemoral cartilage defects.

Similar results were obtained when current anthropometric and body composition measures were examined (table 3 ). Current FM was weakly positively associated with the presence of tibiofemoral cartilage defects $(p=0.07)$, but no effect of FFM $(\mathrm{p}=0.57)$, after adjustment for FFM and FM.

Changes in body weight, BMI, FFM and FM over the time period were not significantly associated with the presence of tibiofemoral cartilage defects, in both univariate and multivariate analyses (table 3 ).

The results were similar when the above analyses were repeated for men and women separately (data not shown).

\section{DISCUSSION}

In this population of healthy community-based adults with no clinical knee OA, baseline (1990-4) and current (2003-4) FFM were both positively associated with tibial cartilage volume, independent of FM. Increase in FFM over the time period was associated with an increase in tibial cartilage volume. In contrast, FM was associated with an adverse effect on knee cartilage. Current FM was associated with reduced tibial cartilage volume, and both baseline and current FM were associated with an increase in tibiofemoral cartilage defects, independent of FFM. Taken together, these findings suggest a beneficial effect of FFM, but a negative effect of FM, on knee cartilage in healthy people.

In this study, we found compelling evidence for a beneficial effect of FFM on cartilage. Both current FFM and FFM measured 10 years earlier were associated with an increased tibial cartilage volume in healthy people independent of FM. It has been shown that increased muscle size and mass is related to increased knee cartilage volume. ${ }^{621}$ We have also recently shown that lower muscle mass is associated with an increased loss of medial and lateral tibial cartilage over 2 years in people without knee OA. $^{6}$ In the present study, we also showed an additional beneficial effect of increase in FFM over time that was associated with increased cartilage volume. These data suggest that increased muscle mass, including gains later in life, may be protective against the loss of cartilage volume. The mechanism by which this occurs is not known but may be due to greater stabilisation at the knee joint during dynamic tasks. The effect of FFM on cartilage volume cannot simply be explained by physical activity, because adjustment for physical activity in the analyses did not change our findings (results not shown). Although it may be that muscle mass and cartilage volume are co-inherited, our finding that an increase in FFM over the time period was associated with increased tibial cartilage suggests that muscle mass is an important determinant of cartilage volume. These data suggest that a change in muscle mass has the capacity to affect changes in cartilage volume.

Obesity is an established risk factor for cardiovascular disease as well as knee OA. ${ }^{2}$ However, unlike for cardiovascular disease, ${ }^{8}$ the distribution of body fat has been inconsistently associated with the risk of knee OA. ${ }^{910}$ A recent crosssectional study showed that BMI, FM, percentage FM and waist circumference were higher in women with OA than in those without, but that there were no differences in WHR between the two groups. ${ }^{22}$ We found that BMI was associated with an increased presence of cartilage defects, which is consistent with a previous study showing a correlation between BMI and an increased prevalence and severity of cartilage defects. ${ }^{23}$ Although BMI is a good measure of body weight, independent of height, it fails to distinguish between adipose and nonadipose body mass. ${ }^{5}$ Our data suggest a negative effect of FM on knee cartilage, with a reduction in volume and an increase in cartilage defects. Moreover, the positive association between FFM and WHR and knee cartilage defects found in this study could be explained by the effect of FM. Cartilage defects have previously been shown to be predictive of cartilage loss, independent of cartilage volume, suggesting a continuum from normal to abnormal cartilage even in healthy people, and that the defects may represent early cartilage abnormalities. ${ }^{15}{ }^{24}$ It is therefore possible that FM may be an important factor in the development and progression of cartilage defects, ultimately leading to longitudinal cartilage loss and knee OA. This may be important in helping to understand the association between obesity and the onset and/or progression of OA.

A potential limitation of this study was the method used to assess body composition. Body composition can be estimated by several different techniques. For instance, lean body mass can be considered a surrogate measure of muscle mass. ${ }^{25}$ In this study, we used FFM, which is the total weight of the body without any fat, referring to all skeletal bones and muscles and other body tissues not containing fat, as a surrogate measure of muscle mass. However, FFM may not always accurately reflect specific changes in muscle mass or differences in muscle mass between individuals. ${ }^{26}$ Nevertheless, our findings persisted after adjustment for age, gender and bone size (tibial plateau bone area), confirming that FFM was a more accurate measure of muscle mass.

A potential strength of our study is that we examined both current body composition as well as data objectively collected about 10 years earlier. This has been recently raised in the context of examining risk factors for OA, particularly in relation to obesity, as any development of symptomatic disease may be associated with a reduction in physical activity and obesity. ${ }^{27}$ In this study we examined asymptomatic people and used a novel methodology that allowed us to examine knee cartilage in a sensitive, validated way. This allowed us, for the first time, to examine cartilage in a continuum from the healthy through to the diseased state so that we can examine the effect of body composition on knee joint morphology in asymptomatic people with no disease or early subclinical disease.

How FFM confers a beneficial effect on knee cartilage whereas FM is associated with a reduction in cartilage and an increase in defects is unclear. The emerging data suggest that beneficial effects of FFM on the joint may be related to biomechanical stabilisation of the joint. ${ }^{67}$ Obesity increases 
joint loading, which may predate cartilage degeneration at weight-bearing sites such as the knee. However, if this were the only explanation, we would expect a similar effect of FFM, which was not the case. Furthermore, our findings that WHR was not associated with an increased presence of tibiofemoral cartilage defects, independent of FM, suggest that this pattern of fat distribution may not be important in OA. However, it has long been recognised that the effect of obesity cannot simply be explained by the biomechanical effect of weight. For example, it has previously been suggested that OA at non-weight-bearing sites such as the carpometacarpal joints and the proximal interphalangeal joints of the hands may be due to metabolic factors related to adiposity. ${ }^{28}$ It may be that hormones such as leptin that indirectly reflect body fat stores and have a role in immunomodulation ${ }^{29}$ may be important in OA. ${ }^{30}$ Chondrocytes from joint cartilage have been shown to express leptin receptors, ${ }^{30} 31$ which, when stimulated, produce nitrous oxide, leading to inflammatory alterations in cartilage including phenotype loss of chondrocytes, apoptosis and metalloproteases activation. $^{32} 33$

In this population of healthy adults, our results suggest a beneficial effect of baseline FFM, current FFM and increase in FFM on tibial cartilage volume over the time period of the study. In contrast, FM was deleterious, being associated with a reduction in tibial cartilage volume and an increase in tibiofemoral cartilage defects independent of FFM. The relative importance of these factors differed according to structure, possibly suggesting different mechanisms of effect. These data suggest that weight-loss programmes aimed at reducing FM but preserving/increasing FFM may be important in maintaining cartilage health, thus preventing the onset and/or progression of knee OA.

\section{Authors' affiliations}

Yuanyuan Wang, Anita E Wluka, Andrew J Teichtahl, Flavia M Cicultini, Department of Epidemiology and Preventive Medicine, Monash University, Central and Eastern Clinical School, Alfred Hospital, Melbourne, Victoria, Australia

Dallas R English, Graham G Giles, Cancer Epidemiology Centre, The Cancer Council of Victoria, Carlton, Victoria, Australia

Richard O'Sullivan, MRI Unit, Mayne Health Diagnostic Imaging Group, Epworth Hospital, Richmond, Victoria, Australia

This study was funded by a programme grant from the National Health and Medical Research Council (NHMRC; 209057) and was further supported by infrastructure provided by The Cancer Council of Victoria. This study was also supported by NHMRC (project grant 334150), Colonial Foundation and Shepherd Foundation. $\mathrm{YW}$ is the recipient of an NHMRC PhD Scholarship. AEW is the recipient of an NHMRC Public Health Fellowship and co-recipient of the Cottrell Fellowship, Royal Australasian College of Physicians.

Competing interests: None.

\section{REFERENCES}

1 Felson DT, Anderson JJ, Naimark A, Walker AM, Meenan RF. Obesity and knee osteoarthritis. The Framingham Study. Ann Intern Med 1988;109:18-24.

2 Hart DJ, Spector TD. The relationship of obesity, fat distribution and osteoarthritis in women in the general population: the Chingford Study. J Rheumatol 1993;20:331-5.

3 Felson DT, Zhang Y, Anthony JM, Naimark A, Anderson JJ. Weight loss reduces the risk for symptomatic knee osteoarthritis in women. The Framingham Study. Ann Intern Med 1992; 1 16:535-9.

4 Sandmark H, Hogstedt C, Lewold S, Vingard E. Osteoarthrosis of the knee in men and women in association with overweight, smoking, and hormone therapy. Ann Rheum Dis 1999;58:151-5.

5 Roubenoff R. Applications of bioelectrical impedance analysis for body composition to epidemiologic studies. Am J Clin Nutr 1996;64:459S-62S.
6 Cicuttini FM, Teichtahl AJ, Wluka AE, Davis S, Strauss BJ, Ebeling PR. The relationship between body composition and knee cartilage volume in healthy, middle-aged subjects. Arthritis Rheum 2005;52:461-7.

7 Slemenda C, Heilman DK, Brandt KD, Katz BP, Mazzuca SA, Braunstein EM, et al. Reduced quadriceps strength relative to body weight: a risk factor for knee osteoarthritis in women? Arthritis Rheum 1998;41:1951-9.

8 Grinker JA, Tucker KL, Vokonas PS, Rush D. Changes in patterns of fatness in adult men in relation to serum indices of cardiovascular risk: the Normative Aging Study. Int J Obes Relat Metab Disord 2000;24:1369-78.

9 Davis MA, Neuhaus JM, Ettinger WH, Mueller WH. Body fat distribution and osteoarthritis. Am J Epidemiol 1990;132:701-7.

10 Hochberg MC, Lethbridge-Cejku M, Scott WW Jr, Reichle R, Plato CC, Tobin JD. The association of body weight, body fatness and body fat distribution with osteoarthritis of the knee: data from the Baltimore Longitudinal Study of Aging. J Rheumatol 1995;22:488-93.

11 Eckstein F, Schnier M, Haubner M, Priebsch J, Glaser C, Englmeier KH, et al. Accuracy of cartilage volume and thickness measurements with magnetic resonance imaging. Clin Orthop 1998:137-48.

12 Wluka AE, Stuckey S, Snaddon J, Cicuttini FM. The determinants of change in tibial cartilage volume in osteoarthritic knees. Arthritis Rheum 2002;46:2065-72.

13 Cicuttini F, Forbes A, Morris K, Darling S, Bailey M, Stuckey S. Gender differences in knee cartilage volume as measured by magnetic resonance imaging. Osteoarthritis Cartilage 1999;7:265-71

14 Jones G, Glisson M, Hynes K, Cicuttini F. Sex and site differences in cartilage development: a possible explanation for variations in knee osteoarthritis in later life. Arthritis Rheum 2000;43:2543-9.

15 Cicuttini F, Ding C, Wluka A, Davis S, Ebeling PR, Jones G. Association of cartilage defects with loss of knee cartilage in healthy, middle-age adults: a prospective study. Arthritis Rheum 2005;52:2033-9.

16 Ding C, Garnero P, Cicuttini F, Scott F, Cooley H, Jones G. Knee cartilage defects: association with early radiographic osteoarthritis, decreased cartilage volume, increased joint surface area and type II collagen breakdown. Osteoarthritis Cartilage 2005;13:198-205.

17 Giles GG, English DR. The Melbourne Collaborative Cohort Study. IARC Sci Publ 2002;156:69-70.

18 Altman R, Asch E, Bloch D, Bole G, Borenstein D, Brandt K, et al. Development of criteria for the classification and reporting of osteoarthritis. Classification of osteoarthritis of the knee. Diagnostic and Therapeutic Criteria Committee of the American Rheumatism Association. Arthritis Rheum 1986;29:1039-49.

19 In:, Lohman TG, Roche AF, Martorell R, eds. Anthropometric standardization reference manual. Champaign, IL: Kinetics Books, 1988:90.

20 Roubenoff R, Baumgartner RN, Harris TB, Dallal GE, Hannan MT, Economos CD, et al. Application of bioelectrical impedance analysis to elderly populations. J Gerontol A Biol Sci Med Sci 1997;52:M129-36.

21 Hudelmaier M, Glaser C, Englmeier KH, Reiser M, Putz R, Eckstein F. Correlation of knee-joint cartilage morphology with muscle cross-sectional areas vs. anthropometric variables. Anat Rec A Discov Mol Cell Evol Biol 2003;270: 175-84.

22 Abbate LM, Stevens J, Schwartz TA, Renner JB, Helmick CG, Jordan JM Anthropometric measures, body composition, body fat distribution, and knee osteoarthritis in women. Obesity (Silver Spring) 2006;14:1274-81.

23 Ding C, Cicuttini F, Scott F, Cooley H, Jones G. Knee structural alteration and BMl: a cross-sectional study. Obes Res 2005;13:350-61.

24 Ding C, Cicuttini F, Scott F, Boon C, Jones G. Association of prevalent and incident knee cartilage defects with loss of tibial and patellar cartilage: a longitudinal study. Arthritis Rheum 2005;52:3918-27.

25 Proctor DN, Melton U, Khosla S, Crowson CS, O'Connor MK, Riggs BL. Relative influence of physical activity, muscle mass and strength on bone density. Osteoporos Int 2000;11:944-52.

26 Proctor DN, O'Brien PC, Atkinson EJ, Nair KS. Comparison of techniques to estimate total body skeletal muscle mass in people of different age groups. Am J Physiol 1999;277:E489-95.

27 Gelber AC. Obesity and hip osteoarthritis: the weight of the evidence is increasing. Am J Med 2003;114:158-9.

28 Cicuttini FM, Baker JR, Spector TD. The association of obesity with osteoarthritis of the hand and knee in women: a twin study. J Rheumatol 1996;23:1221-6.

29 Otero M, Lago R, Lago F, Casanueva FF, Dieguez C, Gomez-Reino JJ, et al. Leptin, from fat to inflammation: old questions and new insights. FEBS Lett 2005;579:295-301.

30 Dumond H, Presle N, Terlain B, Mainard D, Loeuille D, Netter P, et al. Evidence for a key role of leptin in osteoarthritis. Arthritis Rheum 2003;48:31 18-29.

31 Figenschau Y, Knutsen G, Shahazeydi S, Johansen O, Sveinbjornsson B. Human articular chondrocytes express functional leptin receptors. Biochem Biophys Res Commun 2001;287:190-7.

32 Otero M, Gomez Reino JJ, Gualillo O. Synergistic induction of nitric oxide synthase type II: in vitro effect of leptin and interferon-gamma in human chondrocytes and ATDC5 chondrogenic cells. Arthritis Rheum 2003;48:404-9.

33 Kim SJ, Ju JW, Oh CD, Yoon YM, Song WK, Kim JH, et al. ERK-1/2 and p38 kinase oppositely regulate nitric oxide-induced apoptosis of chondrocytes in association with p53, caspase-3, and differentiation status. J Biol Chem 2002;277:1332-9. 